\title{
Absence of an External Germinal Layer in Zebrafish and Shark Reveals a Distinct, Anamniote Ground Plan of Cerebellum Development
}

\author{
Natalie Chaplin, Christian Tendeng, and Richard J. T. Wingate \\ Medical Research Council Centre for Developmental Neurobiology, King's College London, London SE1 1UL, United Kingdom
}

\begin{abstract}
The granule cell layer of the cerebellum comprises the largest population of neurons in the vertebrate CNS. In amniotes, its precursors undergo a unique phase of transit amplification, regulated by Sonic hedgehog. They do so within a prominent but transient secondary proliferative epithelium, the external germinal layer, which is formed by tangential migration of precursor cells from the rhombic lip. This behavior is a hallmark of bird and mammal cerebellum development. Despite its significance for both development and disease, it is unclear whether an external germinal layer is a requirement for granule cell production or an expedient of transit amplification. Evidence for its existence in more basal vertebrates is contradictory. We therefore examined cerebellum development in the zebrafish, specifically in relation to the expression of the basic helix-loop-helix gene Atonal 1, which definitively characterizes granule cell precursors. The expression of Atoh1a-Atoh1c, in combination with patterns of proliferation and fate maps, define precursor pools at the rhombic lip and cerebellar midline but demonstrate that an external germinal layer is absent. Sonic hedgehog signaling is correspondingly absent in the zebrafish cerebellum. Sustained roof-plate-derived signals suggest that, in the absence of transit amplification, primary granule cell precursor pools are maintained throughout development. To determine whether this pattern is specific to zebrafish or reflects a more general anamniote organization, we examined the expression of similar genes in the dogfish, Scylliorhinus canicula. We show that these anamniotes share a common ground plan of granule cell production that does not include an external germinal layer.
\end{abstract}

\section{Introduction}

The cerebellum is a key component of the CNS of all jawed vertebrates (Nieuwenhuys et al., 1998). It has a well characterized role in the comparison of sensory and motor signals and as the site of proprioceptive integration (Sherrington, 1947). The cerebellum is characterized by a very simple, conserved neuronal circuit involving a few defined cell types (Fig. 1). Of these, granule cells comprise not only the major class by number but also the majority of all cells in the CNS. Granule cell development in mammals and birds includes a unique phase of proliferation that bears the hallmarks of transit amplification: committed precursors (Wechsler-Reya and Scott, 1999; Klein et al., 2005) multiply by symmetrical divisions (Espinosa and Luo, 2008) within a prominent, but transient, subpial external germinal layer (EGL) (His, 1890; Schaper, 1897; Ramon y Cajal, 1911) (Fig. 1ii). The EGL is formed by migratory precursors derived from the upper or

Received Dec. 15, 2009; accepted Jan. 8, 2010.

This research was supported by a project grant from the Biotechnology and Biological Sciences Research Council (United Kingdom) and a centre grant from the Medical Research Council (United Kingdom). We thank Laure BallyCuif for materials, Thomas Butts for the construction of the Atoh1 phylogenetic tree, Leah Toole for her thoughtful contributions to the development of this project, Jon Clarke for discussion of the manuscript and help with fatemapping techniques, and Andrew Lumsden for comments on previous versions of this work.

Correspondence should be addressed to Richard Wingate, Medical Research Council Centre for Developmental Neurobiology, King's College London, Fourth floor, New Hunt's House, Guy's Campus, London, SE1 1UL, UK. E-mail: richard.wingate@kcl.ac.uk.

C. Tendeng's present address: Vertebrate Development Laboratory, Cancer Research United Kingdom, Lincoln's Inn Fields, London, WC2A 3PX, UK.

DOI:10.1523/JNEUROSCI.6201-09.2010

Copyright $\odot 2010$ the authors $\quad 0270-6474 / 10 / 303048-10 \$ 15.00 / 0$ cerebellar rhombic lip (Ben-Arie et al., 1997; Wingate and Hatten, 1999): the neuroepithelial boundary of the roof plate of the fourth ventricle (Wingate, 2001).

The EGL has become an important model of neuronal development and is significant as the likely origin of the majority of childhood brain cancers (Kool et al., 2008). EGL proliferation is regulated by Sonic hedgehog (Shh) secreted by the underlying Purkinje cells (Dahmane and Ruiz i Altaba, 1999; Wallace, 1999; Wechsler-Reya and Scott, 1999) (Fig. 1ii). Shh regulates both size and foliation of the cerebellum (Corrales et al., 2006), and mutation of its receptor, patched $(P t c)$, in granule cells results in medulloblastoma (Goodrich et al., 1997). Throughout proliferation, granule cell precursor identity is dependent on expression of the basic helix-loop-helix (bHLH) transcription factor Atonal1 (Atoh1) (Ben-Arie et al., 1996, 1997), which is initially induced by transforming growth factor- $\beta$ (TGF $\beta$ ) signaling at the rhombic lip (Alder et al., 1996, 1999) (Fig. 1i) and only downregulated as postmitotic granule cells exit the EGL (Fig. 1iii).

Vertebrate cerebellar structure differs in both the magnitude and arrangement of a stereotyped complement of cerebellar neurons (Meek, 1992a,b) and glia (Bae et al., 2009). Notably, sharks and sturgeons have a nuclear granule cell organization, whereas an internal granule cell layer is seen in teleosts, amphibians, and all amniotes (reptiles, birds, and mammals) (Nieuwenhuys, 1967; Nieuwenhuys et al., 1998), suggesting these latter groups share a common pattern of development that includes an EGL (Fig. 1). However, studies in the amphibian suggest that, although there is an external granule layer, it is nonproliferative (Gona, 1976). 


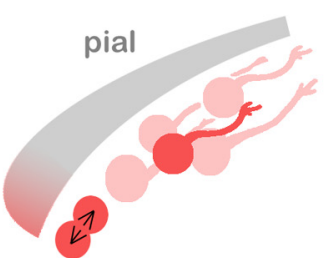

RHOMBIC LIP

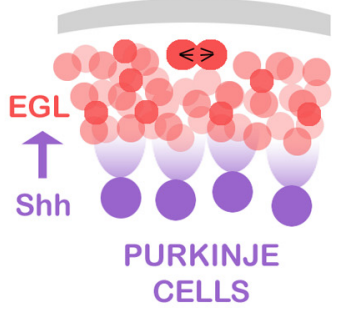

CELLS

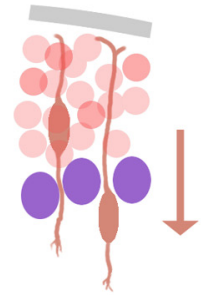

GRANULE CELLS ii) TRANSIT AMPLIFICATION iii) RADIAL MIGRATION

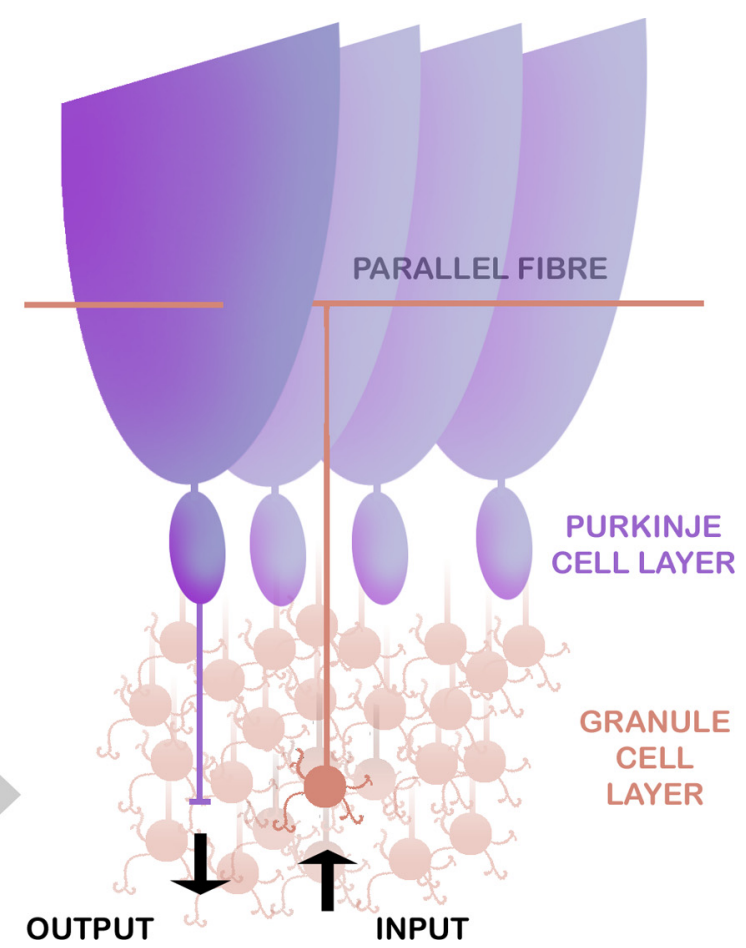

Figure 1. Development of granule cells in relation to Purkinje cells in the amniote cerebellum. Granule cell precursors (red) are initially induced at the rhombic lip by TGF $\beta$ signals ( $g r e e n$ ) from the adjacent roof plate (i). Precursors migrate tangentially over the subpial cerebellar surface and divide again within the transient EGL (ii). Proliferation is regulated by Shh secreted from underlying Purkinje cells (purple). After their last cell division, postmitotic granule cells (brown) radially migrate into a layer below Purkinje cells (iii). In the mature circuit, glutamatergic granule cells receive inputs from precerebellar neurons and project T-shaped axons (parallel fibers) into an almost cell-body-free (molecular) layer, in which they synapse on the dendrites of GABAergic Purkinje cells. Purkinje cell outputs directly and indirectly regulate the activity of the vestibular system, thalamus, and subcortical motor centers.

Moreover, evidence for a secondary proliferation layer in the cerebellum of fish is contradictory (Pouwels, 1978; Adolf et al., 2004; Candal et al., 2005; Mueller and Wulliman, 2005; Zupanc et al., 2005; Grandel et al., 2006; Rodríguez-Moldes et al., 2008; Volkmann et al., 2008; Kaslin et al., 2009).

What then is the relationship between cerebellar organization and the presence of an EGL? We examined this question by assessing zebrafish and the shark for the presence of granule cell transit amplification, defined by (1) secondary proliferation, (2) maintained Atoh1 expression, (3) both at a distance to a source of TGF $\beta$ signaling, and (4) responsive to Shh. The demonstrable absence by these criteria of an external germinal layer in either species implies that transit amplification in the cerebellum is an amniote evolutionary adaptation.

\section{Materials and Methods}

Cloning of Pax6 and Atonall homologs. We constructed $3^{\prime}$ and $5^{\prime}$ rapid amplification of the cDNA ends libraries (Clontech) from a stage 28 (st. 28) embryonic catshark/spotted dogfish, Scylliorhinus canicula. Pax6 was cloned by PCR from its GenBank sequence. Atoh1 was cloned using degenerate, nested forward primers to the region encoding the conserved bHLH motif: atoF1, YTIAAYCAYGCITTYGAY; and atoF2, AARTAYGARACIYTICARATG. Additional 5' sequence was retrieved using the reverse primer TGATTCGTAGGGCAATCTTTCACAT. Danio rerio Atohlc (identification number ENSDARG00000039602) was identified by screening the Ensembl database and cloned using specific forward (ATGCCCCATCCGGACACCCCTTTTGG) and reverse (CTATTTTACACCATTGTTCCTTTCCA) primers.

Histology. Juvenile zebrafish (1-8 d after hatching) and shark embryos (stages 28-33) (Farner, 1978) were collected and fixed in paraformaldehyde (4\% in PBS) and processed for in situ hybridization using standard protocols, with riboprobes for the following: Atoh1a, Atoh1b, Gdf7, Gfd6a, Atoh1c, Zic1, Shha, Shhb, Ptc1, and N-myc (zebrafish) and Atoh1,
Pax6, Shh, and Ptc2 (shark). Embryos were transversely sectioned after embedding in methacrylate resin (zebrafish), paraffin (shark), or gelatin (shark). Whole mounts and paraffin sections were processed for immunohistochemistry with primary antibodies to phosphohistone $\mathrm{H} 3(1: 100$; Cell Signaling Technology) or Zebrin II (1:100; a gift of Richard Hawkes, University of Calgary, Calgary, Alberta, Canada) and appropriate peroxidase-conjugated secondary antibodies and then counterstained with methyl green (resin), cresyl violet, or hemotoxylin/eosin (paraffin).

Acute fate mapping in zebrafish with Kaede. Capped Kaede RNA was injected into zebrafish at the one-cell stage ( $100 \mathrm{ng})$. After 3-5 d, fish were screened for (green) Kaede expression, and spatially identified cells within the cerebellum of anesthetized fish $(0.01 \%$ Tricaine) were selectively illuminated by blue laser line $(351 \mathrm{~nm} / 364 \mathrm{~nm})$. The distribution of photoconverted (red) cells was monitored by confocal microscopy for 16-48 h (Nikon Eclipse 80i). Maps of photoconverted cells were compiled by tracing the area of red label directly from confocal micrographs (in Adobe Photoshop; Adobe Systems). The opacity of each trace was divided by the number of fate maps and placed into separate layers on a standardized template.

\section{Results}

In amniotes, granule cells are derived from proliferative Atoh1positive (Ben-Arie et al., 1997) precursor cells at the rhombic lip and subsequently in the EGL. We cloned and contrasted previously undescribed homologs of Atoh1 in zebrafish and shark to provide a comprehensive picture of granule cell origins in these representative teleost and chondrychthyan species.

\section{Atoh1 and proliferation zones in the developing zebrafish cerebellum}

Although its territory is allocated by patterning mechanisms similar to those in other vertebrates (Reifers et al., 1998), the teleost cerebellum has a distinct structure that comprises an upper 
rhombic lip, a main body or "corpus," and a rostral apex known as the valvulus (Fig. 2a) (Nieuwenhuys et al., 1998; Mueller and Wulliman, 2005; Bae et al., 2009). We examined the expression of Atohla and Atoh $1 b$ in relation to these structures, using the expression of phosphohistone $\mathrm{H} 3$ as a marker of cells undergoing proliferation. At $2 \mathrm{~d}$, both Atohla and Atoh $1 b$ are expressed within both the upper rhombic lip adjacent to the cerebellum and lower rhombic lip of the hindbrain (Fig. $2 b$; because expression of Atohla and Atohlb is identical within the cerebellum at all stages examined, only Atohla is shown in this and subsequent figures). Together, the lower and upper rhombic lip(s) form a continuous, diamond-shaped boundary at the edge of the roof plate of the fourth ventricle. The rhombic lip also expresses Zic1 (Fig. 2c) as in chick and mouse but not Pax6a (data not shown) or Pax6b (Fig. 2d). Expression of Atoh1a/b also extends rostrally along the midline of the future cerebellar plate (corpus) into the presumptive valvulus, which comprises the apical, rostral pole of the dorsal cerebellum (Fig. 2e). Proliferating cells are concentrated both here and within the Atohla-positive cerebellar midline (Fig. $2 f$ ) and upper rhombic lip (Fig. 2g). At $2.5 \mathrm{~d}$, Atoh $1 \mathrm{a} / \mathrm{b}$ expression begins to be downregulated in all but the presumptive valvulus (Adolf et al., 2004) (Fig. $2 h--j$ ). At $5 \mathrm{~d}$, proliferation is essentially absent from the now distinct main corpus of the cerebellum (Fig. $2 l$ ) but maintained in the valvulus (Fig. $2 k$ ) and the upper rhombic lip (which no longer expresses Atohla/b) (Fig. 2m).

The Atoh1-positive precursor pool is not coextensive with the granule cell layer

In amniotes, rhombic lip derived granule cell precursors migrate away from the roof plate and assemble in a transient Atoh1positive EGL. Cells undergo a series of symmetric divisions (Espinosa and Luo, 2008) before migrating radially into the cerebellum. The spatial dimensions of the Atoh1-postive EGL thus define the extent of the future granule cell layer. We therefore examined the distribution of Atohla/b in relation to the distribution of granule cells to assess whether these orthologs define a candidate EGL.

We compared Atoh $1 \mathrm{a} / \mathrm{b}$ expression with that of Zicl, a marker of both rhombic lip and its granule cell derivatives (Aruga et al., 1998) with respect to presumptive territories of the zebrafish cerebellum (Fig. 3a). At $3 \mathrm{~d}$, the expression domains of Atohla/b at the apical midline (presumptive valvulus) becomes spatially distinct to that of Zicl (Fig. 3b) and excluded from the corpus of the cerebellum as the granule cell layer, which also expresses
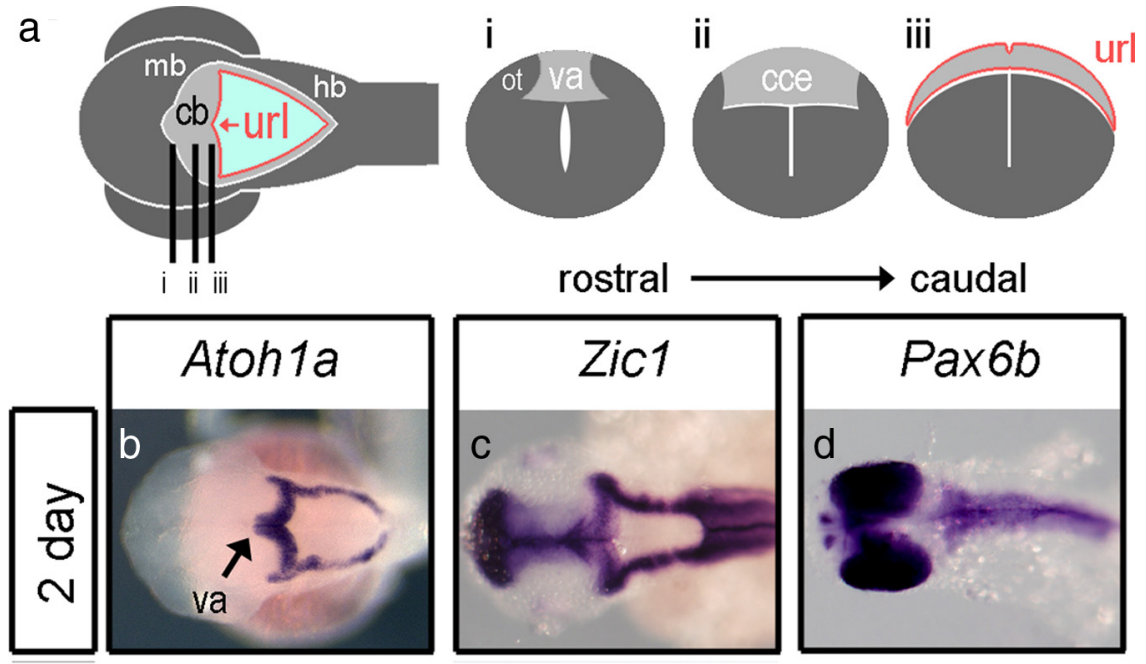

caudal
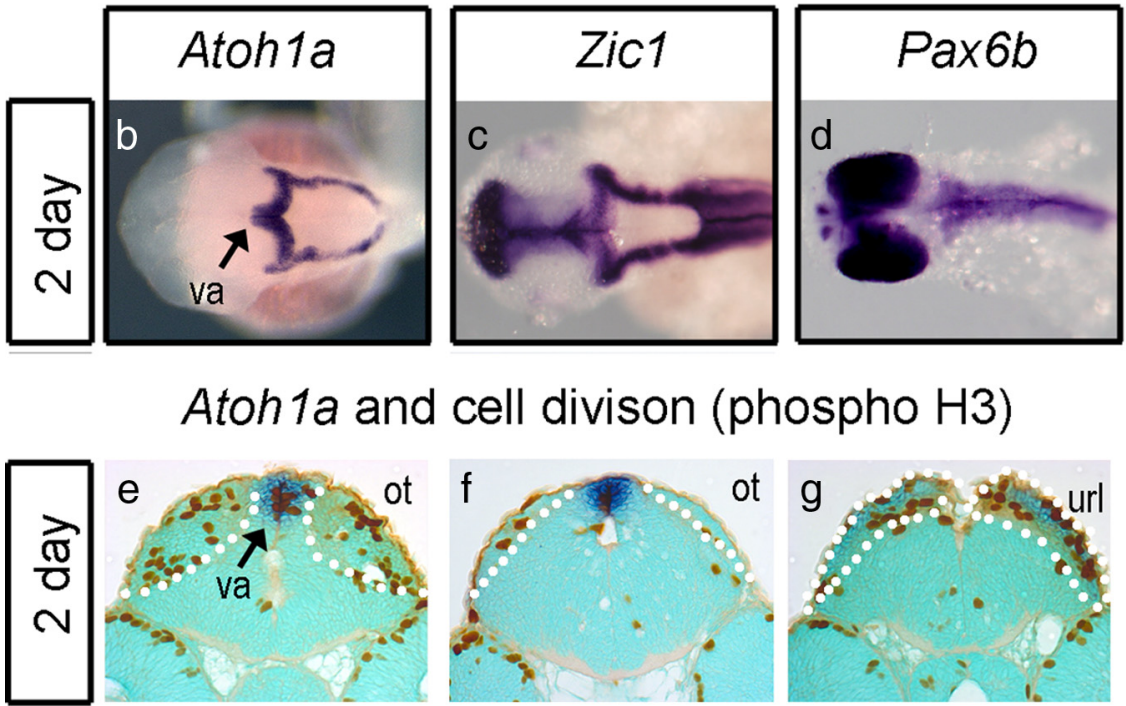

\section{Atoh1a and cell divison (phospho H3)}
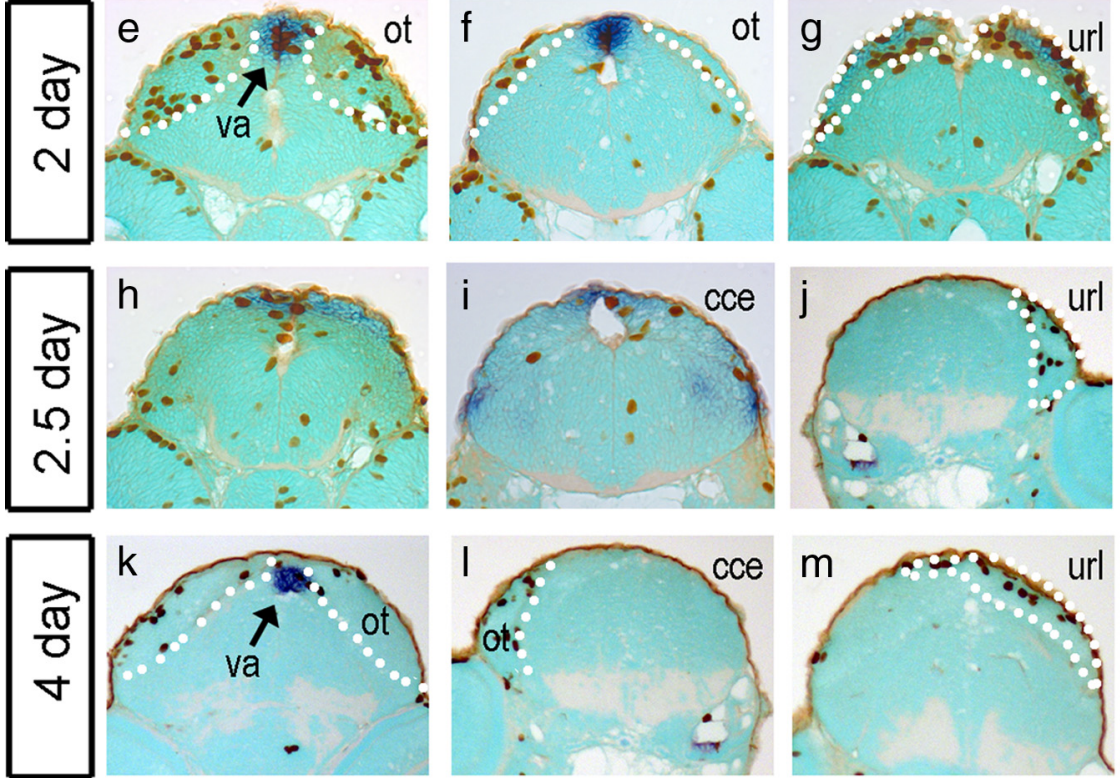

ii
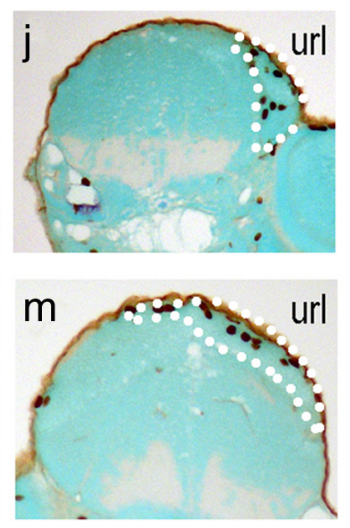

iii

Figure 2. Atoh1a and proliferation in the zebrafish. Schematic dorsal view $(\boldsymbol{a})$ of a 5 d embryonic zebrafish shows cerebellar and precerebellar territory in gray, the rhombic lip at the edge of the fourth ventricle in red, and roof plate in light blue. The cerebellar or upper rhombic lip (url) is the portion that borders the cerebellum (cb), which lies between the dorsal lobes of the optic tectum (ot) of the midbrain (mb) and hindbrain (hb). Lines indicate the level of sections through the presumptive valvulus (i) (va), the corpus of the cerebellum (ii) (cce), and the upper rhombic lip (iii). At $2 \mathrm{~d}(48 \mathrm{~h}$ ), before the corpus is defined, Atoh 1a (blue) is expressed throughout the rhombic lip of both the cerebellum and hindbrain $(\boldsymbol{b})$ in the same domain as Zic7 (c). Pax6a (data not shown) and Pax6b (d) are not expressed in the rhombic lip. In transverse section, proliferative (phosphohistone H3; brown), Atoh1-positive cells are seen at the valvulus (e), flanked by dividing cells in the dorsal midbrain comprising the optic tectum (ot), at the cerebellar midline $(\boldsymbol{f})$ and at the Atoh1a-positive upper rhombic lip $(\boldsymbol{g})$. At $2.5 \mathrm{~d}$, proliferating cells are seen in the Atoh1apositive presumptive valvulus $(\boldsymbol{h})$ and in regions in which Atoh 1 is downregulated: the midline of the main corpus cerebellar $(\boldsymbol{i})$ and the url $\left(\boldsymbol{( j )}^{j}\right.$. A similar pattern is observed at $4 \mathrm{~d}$ with infrequent division at the cerebellar midline $(\boldsymbol{k}-\boldsymbol{m})$. Dotted white lines indicate the boundaries of cerebellar territory.

Pax6a (data not shown), emerges. At $4 \mathrm{~d}$ (Fig. 3c) and $5 \mathrm{~d}$ (Fig. $3 d$ ), Atohla/b expression remains restricted to the presumptive valvulus. In dorsal view at $3 \mathrm{~d}, \mathrm{Zicl}$ is expressed throughout the rhombic lip and abuts the domain of Atoh $1 a / b$ at the cerebellar midline (Fig. 3e). The formation of a layer of Zicl-positive granule cells at $4 \mathrm{~d}$ (Fig. $3 f$ ) to $5 \mathrm{~d}$ (Fig. $3 g$ ) within the corpus of the cerebellum correlates with a downregulation of $Z i c 1$ within the hindbrain rhombic lip. At no point do the expression domains of 
a

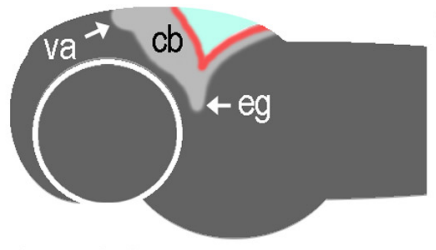

lateral view
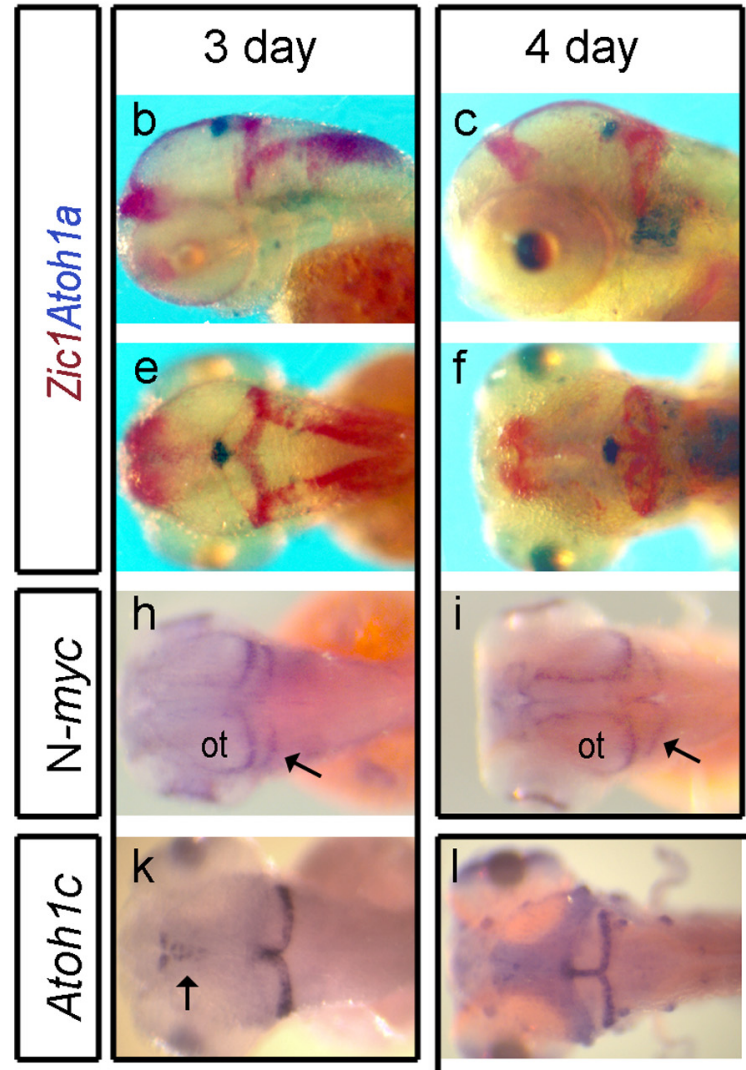

Atoh1c
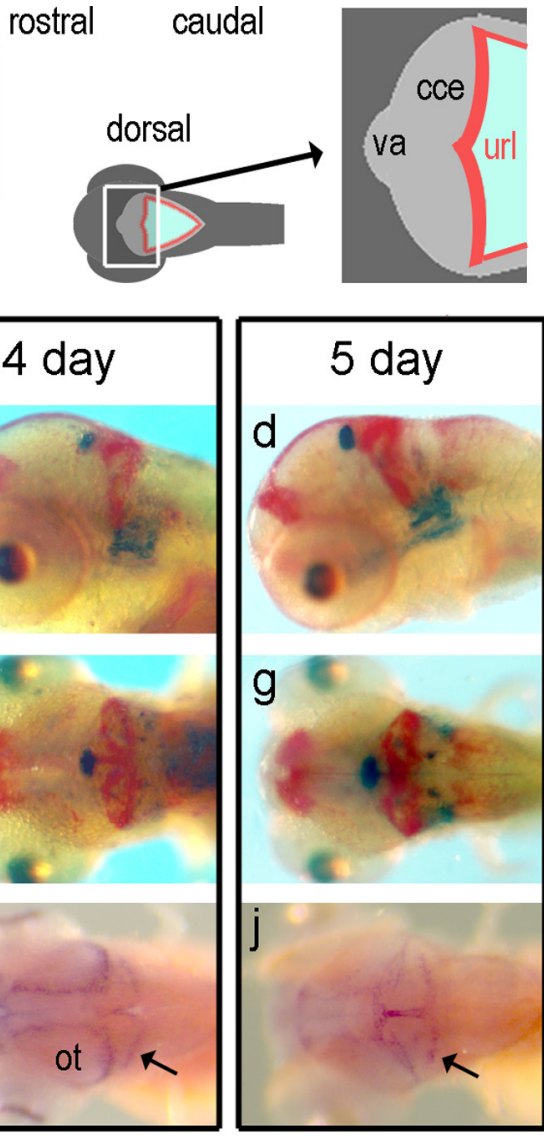

$\mathrm{m}$

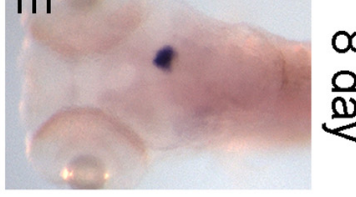

Atoh1a

Figure 3. Atoh1a and Atoh1c in relation to granule cell formation in zebrafish. Schematic lateral view of a zebrafish embryo (a) and expanded dorsal representation of the cerebellum showing the position of the valvulus (va) relative to the corpus of the cerebellum (cce) and upper rhombic lip (url), whose lateral extensions comprise the granule cell eminences (eg). In $\boldsymbol{b}-\boldsymbol{g}$, Atoh1a (blue) is contrasted with Zic 1 (red) in lateral view at $3 \mathrm{~d}(\boldsymbol{b}), 4 \mathrm{~d}(\boldsymbol{c})$, and $5 \mathrm{~d}(\boldsymbol{d})$ and dorsal view at $3 \mathrm{~d}(\boldsymbol{e}), 4 \mathrm{~d}(\boldsymbol{f})$, and $5 \mathrm{~d}(\boldsymbol{g})$. N-myc is expressed within caudal margin of the optic tectum (ot) and upper rhombic lip at $3 \mathrm{~d}(\boldsymbol{h})$, expanding into the midline of both at $4 \mathrm{~d}(\boldsymbol{i})$ to include the valvulus at $5 \mathrm{~d}(\boldsymbol{j})$. Atoh 1c-positive cells $(\boldsymbol{k})$ are found in the upper rhombic lip from $3 \mathrm{~d}$ onward. At $8 \mathrm{~d}(\boldsymbol{I})$, Atohic expression is also seen in anterior lateral line neuromasts and occupies a complementary domain to valvular Atoh1a expression $(\boldsymbol{m})$ in the cerebellar midline.

Atohla/b (presumptive granule cell precursors) and Zicl (definitive granule cells) overlap in a manner that suggest an external germinal layer.

We also examined the expression of $\mathrm{N}-m y c$, which characterizes proliferating cells within the mammalian EGL (Knoepfler et al., 2002) downstream of Shh signaling (Kenney et al., 2003; Hatton et al., 2006). As reported previously in the $3 \mathrm{~d}$ zebrafish (Loeb-Hennard et al., 2005), high levels of N-myc characterize the posterior margin of the tectum and upper rhombic lip (Fig. $3 h$, arrow). As the cerebellar territory expands, $\mathrm{N}-m y c$ expression is co-opted into the cerebellar midline (Fig. 3i). By $5 \mathrm{~d}, \mathrm{~N}-m y c$ is expressed in the valvulus, midline, and cerebellar rhombic lip (Fig. 3j). At no point during granule cell formation is $\mathrm{N}-m y c$ expressed in a superficial layer within the cerebellum.
These patterns of proliferation and expression raise doubts as to the status of the reported external germinal layer in zebrafish (Mueller and Wulliman, 2005). Atoh $1 a / b$ marks only a subset of proliferating cells (in the presumptive valvulus). Proliferating cells at the upper rhombic lip that have been shown to generate granule cells (Volkmann et al., 2008) are, in contrast, Atoh1 negative. Neither the distribution of Atoh1 nor that of dividing cells is consistent with a superficial EGL that might give rise to definitive granule cells by radial migration.

One explanation is that there are additional versions of Atoh1 within the zebrafish genome, one of which would identify an EGL that overlies the Zicl domain. Accordingly, we searched available databases and identified and cloned an additional ortholog, Atoh1c. Its expression in the zebrafish cerebellum is initiated in the upper rhombic lip and cerebellar midline at $3 \mathrm{~d}$ (Fig. $3 k$ ), similar to that of Pax6b (data not shown). Atoh1c persists in this domain to the latest stage examined ( $8 \mathrm{~d}$ ) (Fig. $3 l$ ), as does the Atoh $1 a / b$ expression at the midline (Fig. $3 m$ ), but does not spread over the surface of the cerebellum. The absence of a superficial layer of both cell proliferation and Atoh1 expression in the developing cerebellum argues against the presence of an EGL.

\section{The cerebellar midline gives rise to tangentially migrating cells}

The domain of Atohlc encompasses the upper rhombic lip, which gives rise to tangentially migrating cells (Köster and Fraser, 2006; Volkmann et al., 2008). However, the combined domains of Atohla/b and Atohlc extend beyond the upper rhombic lip into the cerebellar midline and presumptive valvulus. Do these regions also contribute tangentially $\mathrm{mi}-$ grating derivatives to the cerebellum?

To investigate this possibility, we used the photoconvertible green protein, Kaede (Ando et al., 2002), to fate map small clusters of cells by a spatially localized illumination with a blue laser. Red-labeled derivatives of this photoconverted cluster were examined $12 \mathrm{~h}$ (Fig. $4 b)$ to $48 \mathrm{~h}$ later. Photoconversion of the apical cerebellar midline (presumptive valvulus) always resulted in a bilateral label within the corpus of the cerebellum and a narrow trail of cells at the cerebellar midline (Fig. $4 a, 3 \mathrm{~d}$ ). Time-lapse imaging of cell dispersal suggests an active, bilateral, tangential migration (Fig. $4 c$ ) (supplemental movie, available at www.jneurosci.org as supplemental material), with derivatives demarcating the range of migration within the first hour of filming. This bilateral distribution of cells can be seen in the superimposed maps of cell dispersal from the presumptive valvulus at $2 \mathrm{~d}($ Fig. $4 d, n=9)$ and $3 \mathrm{~d}$ (Fig. $4 e, n=10$ ). The cell movements comprising these lateral (dorso- 


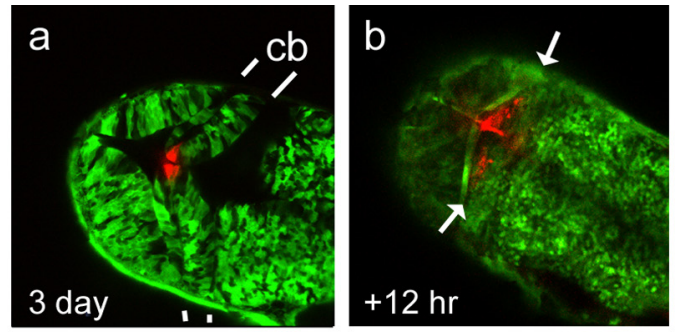

C
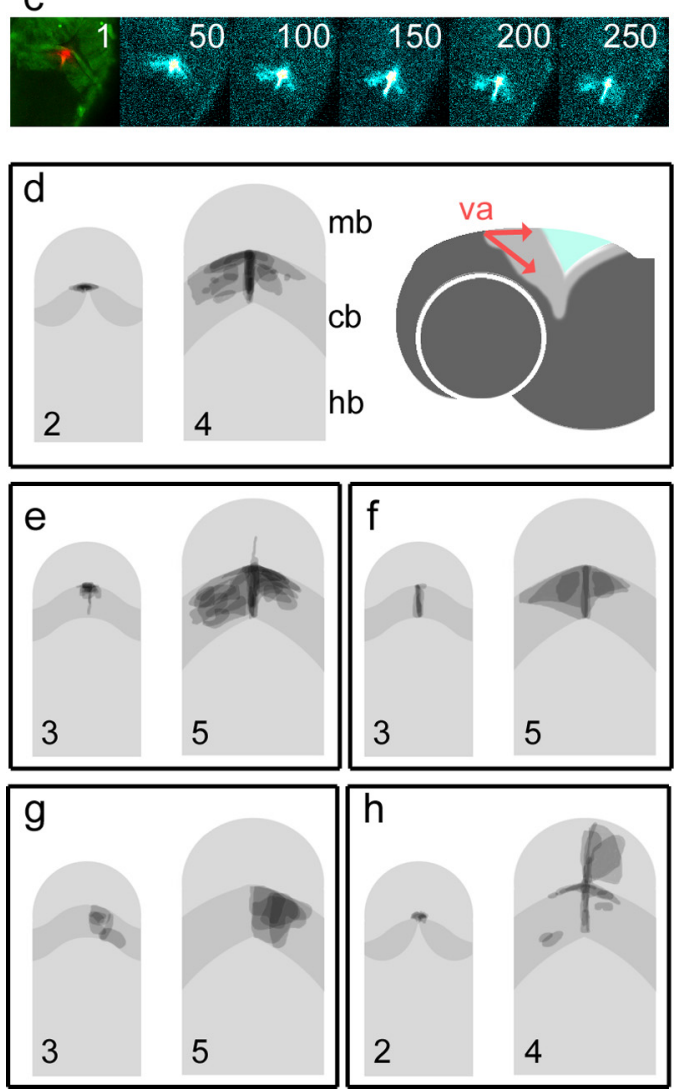

Figure 4. Fate maps of midbrain and cerebellar precursor pools in zebrafish. Kaede RNA was injected into embryos at the one-cell stage to produce green fluorescent fish. Optical sectioning with a laser scanning confocal microscope reveals the cerebellum in dorsal view with clearly demarcated rostral and caudal boundaries (indicated by white lines). Photoconversion of cells at the presumptive valvulus (red) (va) of the cerebellum (cb) at $72 \mathrm{~h}$ (a) gives rise to symmetrically dispersed label $12 \mathrm{~h}$ later (arrows in $\boldsymbol{b}$ ) within the unconverted, green-labeled cerebellum. Sequence (c) of confocal projections (11 optical sections) showing the spread of photoconverted cells over time. Frame numbers represent 5 min intervals. Frames 50-250 show photoconverted cells enhanced with a "thermal" color look-up table. Although the spatial domain occupied by the label spans the width of the cerebellum, the accompanying time-lapse sequence of 270 frames (supplemental movie, available at www.jneurosci.org as supplemental material) shows the continuous migration of midline derivatives replenishing the cerebellum. $\boldsymbol{d}-\boldsymbol{h}$ show superimposed fate maps from a set of experiments in which cells were photoconverted at either 2 or $3 \mathrm{~d}$ and imaged after $48 \mathrm{~h}$. Pairs of images show fate maps (right) grouped according to the location of labeled precursors (shown on left). The cerebellum is shown in dark gray. The valvulus of the cerebellum was labeled at $2 \mathrm{~d}(\boldsymbol{d})$ and $3 \mathrm{~d}$, producing comparable, bilateral streams of cells as seen in $\boldsymbol{a}-\boldsymbol{c}$. To the right, a schematic lateral view shows direction of cell distribution from the valvulus (red). Bilateral derivatives were seen after photoconversion of the cerebellar midline $(\boldsymbol{f})$ but not the corpus of the cerebellum $(\boldsymbol{g})$. Photoconversion of the caudal midline of the midbrain adjacent to the valvulus at $2 \mathrm{~d}(\boldsymbol{h})$ labeled derivatives in both the cerebellar and midbrain midline, as well as cells within the optic tectum. Rostral is to the top in all panels. $\mathrm{Hb}$, Hindbrain; mb, midbrain.

ventral) and midline streams from the valvulus are shown schematically in Figure $4 d$ (right). Cerebellar midline caudal to the presumptive valvulus also gives rise to bilateral streams of cells (Fig. $4 f, n=4)$. In contrast, clones of labeled cells within the corpus of the cerebellum are always restricted to one or other hemisphere (Fig. $4 g, n=6$ ), indicating that the cerebellar midline is a barrier to interhemispheric cell movement.

Together, time-lapse movies and the symmetry and range of cell movement suggest that cell dispersal from the cerebellar midline is by active, tangential migration, as seen in the upper rhombic lip (Volkmann et al., 2008). This contrasts markedly with that of cells from the dorsal midline of the midbrain at $2 \mathrm{~d}$, which always generates asymmetrically distributed clones, more suggestive of a passive clonal spread (Fig. $4 h, n=5$ ). In a manner reminiscent of chick isthmic development (Alexandre and Wassef, 2003), caudal midbrain precursors (at 2 d) also give rise to cells in the cerebellar midline. These cells do not give rise to tangential migrants, suggesting that the widespread derivatives seen in Figure $4 f$ are generated only by midline cells derived from the cerebellum.

\section{Shh and $G d f$ expression in the developing zebrafish cerebellum}

Proliferative cells at the midline and presumptive valvulus express Atoh 1 and give rise to migratory derivatives. This suggests that these cells might constitute an EGL. Whereas at the rhombic lip the induction of granule cell precursors is regulated by TGF $\beta$ signaling from the roof plate, their transit amplification of granule cells in the EGL is maintained by Shh expression in underlying Purkinje cells (Dahmane and Ruiz i Altaba, 1999; Wallace, 1999; Wechsler-Reya and Scott, 1999). Shh signaling is an integral part of the signaling network that maintains the EGL and regulates cerebellar size in amniotes (Corrales et al., 2006). We therefore examined the expression of Atoh1 in relation to diffusible roofplate-derived TGF $\beta$ signals, Gdf6a and Gdf7 (Davidson et al., 1999; Elsen et al., 2008), and both Shh homologs and their receptor, Ptc1, whose expression correlates with Shh signal transduction (Pearse et al., 2001).

Neurally expressed Shh homologs, Shha (Fig. 5a) and Shhb (Fig. 5b), are excluded from the cerebellum at all stages examined (to $5 \mathrm{~d}$ ). Ptc1 is also absent from the cerebellum (Fig. $5 c$ ), suggesting that cerebellar neurons are not transducing Shh signals as the granule cell layer expands. Coronal sections confirm that Shha (Shhb not shown) and Ptcl are expressed, respectively, within the hindbrain midline (Fig. $5 d$ ) and within the hindbrain midline and in adjacent neuroepithelium (Fig. $5 e$ ) but not the cerebellum. In contrast, $G d f 7$ and $G d f 6 a$, which are expressed in the rhombic lip at earlier stages (data not shown) (Elsen et al., 2008), show a prolonged expression (to at least $8 \mathrm{~d}$ ) in the valvulus (Fig. $5 f, g$, Gdf7), cerebellar midline, and upper rhombic lip (Fig. 5h, $G d f 6 a$ ). Curiously, the distinct spatial domains of $G d f 7$ and $G d f 6 a$ correlate with the perdurant expression domains of Atohla/b (Fig. 5g) and Atoh1c (Fig. 5i), respectively. For Gdf6a/Atoh1c, this registration extends to their expression in a subset of anterior lateral line neuromasts (Fig. $5 h, i$, arrows). Chromosome location gives no evidence of genetic linkage between these pairs of genes.

Our analysis of zebrafish development suggests that the strategy for generating a granule cell layer deviates markedly from amniotes. A distinct Atoh1-positive, proliferative layer equivalent to an EGL is absent. Moreover, there is no Shh signaling in the cerebellum, although the coexpression of $G d f$ and Atohl into late stages suggests a prolonged dorsal induction of rhombic lip tissue. To determine whether this organization is a secondarily derived teleost characteristic or reflects a more widespread basal program of cerebellum development, we examined the origins of granule cells in a chondrychthyan: the catshark/dogfish, S. canicula. 

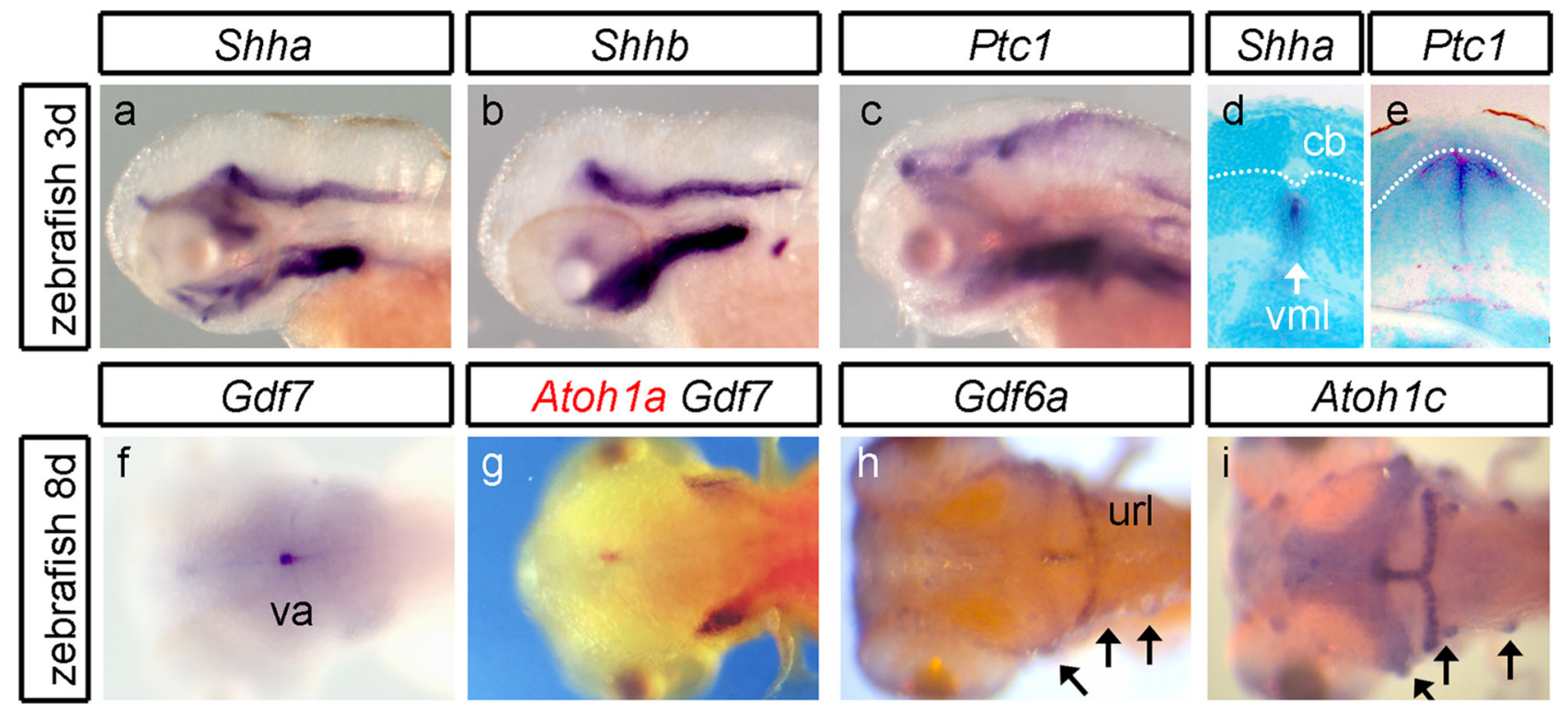

Figure 5. Lack of Shh signaling in the zebrafish cerebellum. In lateral view, neither Shha (a), Shhb (b), nor Ptc1 (c) are expressed in the cerebellum at $3 \mathrm{~d}$ development or at any stage through to $8 \mathrm{~d}$ (data not shown). In transverse section, Shha (d) is expressed at the ventral midline (vml) of the hindbrain. Ptc $1(\boldsymbol{e})$ is expressed in both the ventral midline and surrounding ventral tissue but not in the cerebellum (cb). Dorsal view at $8 \mathrm{~d}$ shows Gdf7 (f) expressed in the valvulus (va). Double in situ hybridization (g) shows that Gdf7 (blue) and Atoh1a (red) domains abut. In the CNS, Gdf6a ( $\boldsymbol{h}$ ) and Atohic $(\boldsymbol{i})$ are expressed in the same spatial domain comprising the upper rhombic lib (url) and cerebellar midline. They are also coexpressed within a subset of anterior lateral line neuromasts (arrows).

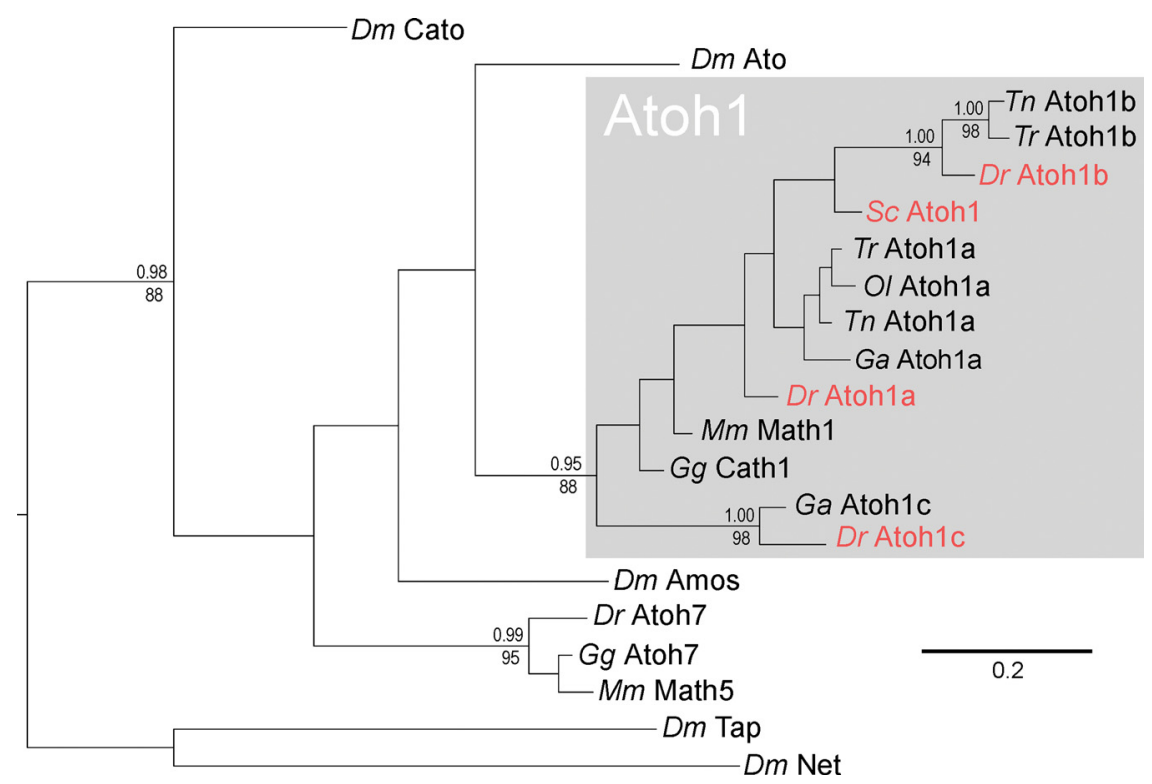

Figure 6. Phylogenetic relationships of vertebrate atonal genes. The phylogenetic tree shown was derived by Bayesian analysis of the aligned bHLH region and is rooted with the Drosophila bHLH genes tap and net. A very similar topography was also recovered using maximum likelihood reconstruction. Support values above nodes represent Bayesian posterior probabilities, and those below nodes represent bootstrap percentages of 1000 pseudoreplicates. Values are given for all nodes that were significantly supported in both analyses $(p>0.95$ and $b>70)$. Genes shown in red are examined in this study. Dm, Drosophila melanogaster; Dr, Danio rerio; Ga, Gasterosteus aculeatus; Gg, Gallus gallus; Mm, Mus musculus; Ol, Oryzias latipes; Sc, Scyliorhinus canicula; Tn, Tetraodon nigroviridis; Tr, Takifugu rubripes.

\section{Cerebellar Atoh1 expression in the shark resembles that in zebrafish}

The chondrychthyan cerebellum displays distinctive morphology: granule cells are arranged into prominent midline eminences (Nieuwenhuys, 1967; Nieuwenhuys et al., 1998), which span the entire axis of a bag-like cerebellum. To investigate how this organization arises, we first screened an S. canicula cDNA library for Atoh1 by PCR amplification and discovered a single ortholog. The relationship between the conserved bHLH sequences of Atoh1 is shown in the phylogenetic tree in Figure 6. Shark Atoh1 is clearly orthologous to Atoh1 in other vertebrates. Of the euteleost Atoh paralogs, Atohla has been retained in all fish genomes sequenced to date. Atohlb is only found in pufferfish (Tetraodon nigroviridis and Takifugu rubripes) and zebrafish (Danio rerio), and Atoh1c is found only in zebrafish and stickleback (Gasterosteus aculeatus). Shark (S. canicula) Atoh1 predates the origin of these paralogs, which probably reside at the common ancestor of the euteleosts, perhaps as a result of a genome duplication followed by a subsequent gene duplication.

We focused our examination of shark development between stages (Farner, 1978) 27 and 32 (Fig. 7a) when granule cell midline condensations become morphologically distinct in S. canicula (Rodríguez-Moldes et al., 2008). At st. 28, phosphohistone $\mathrm{H} 3$ labeling reveals uniform proliferation rates throughout the ventricular surface of the presumptive cerebellum (Fig. 7b). By st. 32, highest rates of division are seen at the cerebellar midline (Fig. 7c) and upper rhombic lip (data not shown), medial to the midline granule cell condensation (shown schematically in Fig. 7a). Zebrin immunolabel shows that Purkinje cells accumulate lateral (embryonic ventral) to granule cell eminences (Fig. 7d).

At st. 27, the expression of Atoh1 maps the spatial extent of the rhombic lip and domains adjacent to cerebellar midline (Fig. 7e) 
and from st. 27 onward is never seen in a layer over the surface of the cerebellum. Atoh1 is excluded from the midline of the cerebellum midline itself (Fig. $7 g$ ) and defines a discrete pool of rhombic lip precursors, which abuts the roof plate of the hindbrain (Fig. 7h). We used the expression of Pax6 as a marker of definitive granule cells (Rodríguez-Moldes et al., 2008). As in zebrafish, at early stages, $P a x 6$ is expressed in ventral hindbrain (Fig. 7i) and excluded from the cerebellum (Fig. $7 i, j)$ and hindbrain rhombic lip (Fig. 7k), which only transiently expresses Pax6 at st. 28 (Fig. $7 k$, inset). We were unable to detect Atoh1 at later stages (after st. 29), but at st. 32, Pax6-positive granule cells have accumulated on either side of the midline in cerebellum (Fig. $7 l$ ) and in the upper rhombic lip or auricles (Fig. $7 l, m$, $\mathrm{au}$ ). The auricles and cerebellar midline are continuous and hence comprise a tightly folded linear aggregation of granule cells that extends throughout the extent of the corpus of the cerebellum (Fig. $7 m$, cce). In cross-section (Fig. $7 n$ ), the bilateral swellings on either side of the cerebellar midline are uniformly Pax6 positive, except for a thin superficial layer at the pial surface.

In contrast to the zebrafish, we detected Shh expression (at st. 32) in the developing shark cerebellum (Fig. 7o). Shh was restricted to two bands of expression lateral (embryonic ventral) to the granule cell eminences throughout the length of the corpus of the cerebellum (but not the upper rhombic lip). In section, Shh is restricted to pial, postmitotic neurons (Fig. $7 p$ ) that correspond to the location of the most medial Purkinje cell populations (Fig. $7 d$ ). We used expression of the Shh receptor Ptc2 (Dahn et al., 2007) to determine which cells transduce $S h h$. In dorsal view, Ptc2 is weakly expressed in a similar domain to Shh (Fig. 7q). In transverse section, Ptc2 is expressed in the ventricular layer, directly beneath the band of Shhpositive Purkinje cells, lateral to the granule cell eminence (Fig. 7r). Although we cannot determine whether these are precursors of Shh-producing Purkinje cells themselves, precursors lateral to the granule cell precursor domain are candidates for producing a range of cerebellar GABAergic interneurons that include Purkinje cells.

These observations are summarized as a schematic diagram in Figure $7 s$. It seems likely that granule cell production is restricted to the region on either side of the midline in a separate domain to Purkinje cells and other interneurons. Just lateral to the granule cell eminences, there is a
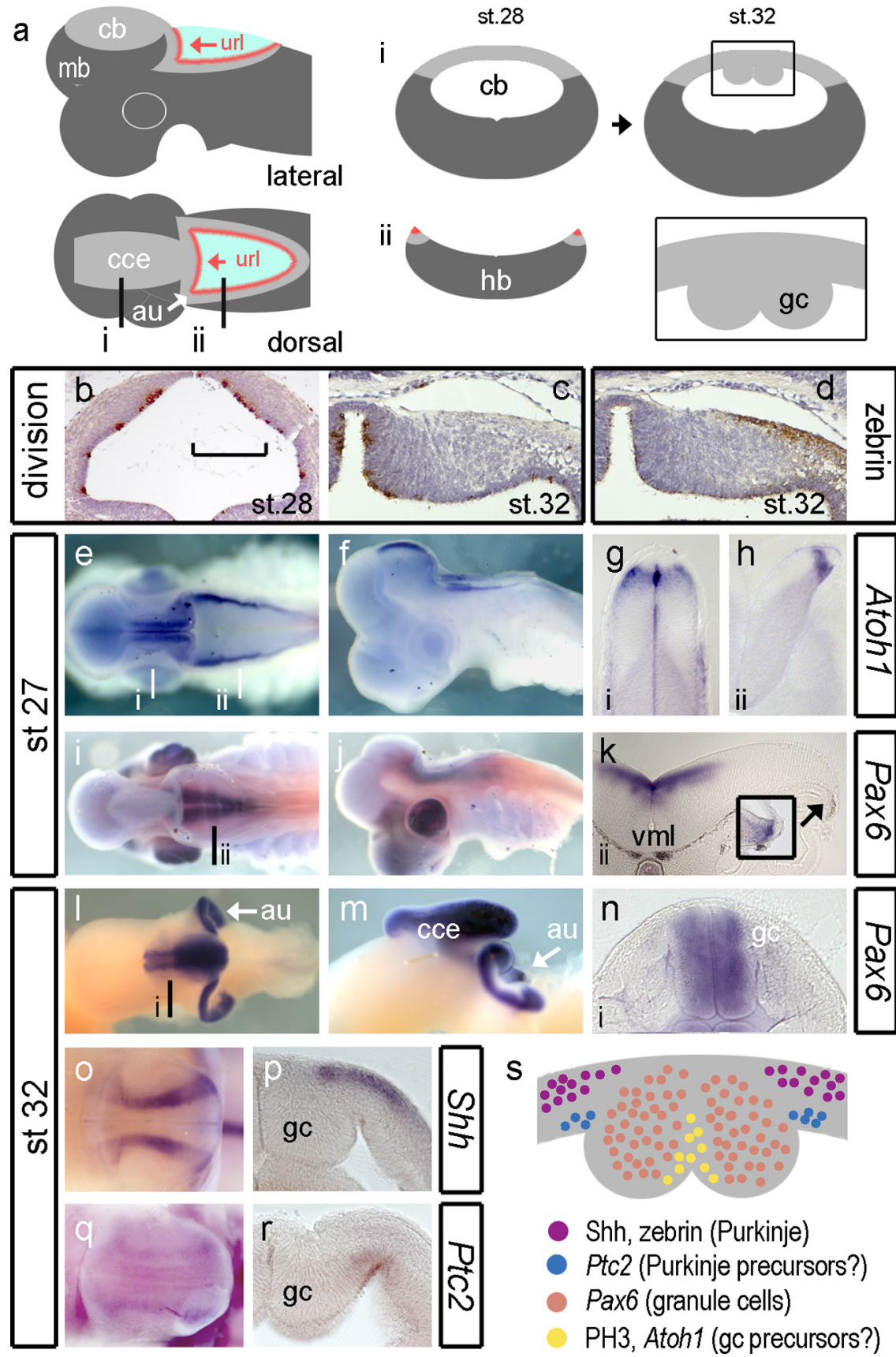

Figure 7. Development of granule cells in the shark cerebellum. Schematic dorsal and lateral views (a) of the shark cerebellum show the relationship of the corpus of the cerebellum (cce) to the upper rhombic lip (url) whose lateral extensions comprise the cerebellar auricles (au) (white arrow). Levels of transverse sections through the cerebellum (i) (cb) and hindbrain (ii) $(\mathrm{hb})$ are indicated on the dorsal plan. Schematic profiles for these sections are shown for a st. 28 embryo (middle). At st. 32, in schematic transverse section (right), the cerebellar midline shows prominent thickenings (boxed area) comprising accumulated postmitotic granule cells (gc) (Meek, 1992b; Nieuwenhuys et al., 1998; Rodríguez-Moldes et al., 2008). Cell proliferation (brown indicates phosphohistone $\mathrm{H} 3$ positive) in the neural tube at the level of the presumptive cerebellum at st. 28 (b) and unilaterally at the dorsal midline st. 32 (c). The medial extent of the Zebrin-positive domain of Purkinje cells coincides with the boundary of the midline eminences (d). At st. 27, Atoh1 in whole-mount dorsal (e) and lateral $(\boldsymbol{f})$ view. Transverse sections indicated in $\boldsymbol{a}$ show Atoh 1 adjacent to the cerebellar midline $(\boldsymbol{g})$ and at the rhombic lip $(\boldsymbol{h})$. In contrast, Pax6 in dorsal $(\boldsymbol{i})$ and lateral $(\boldsymbol{j})$ view is restricted to the ventral hindbrain and absent from the rhombic lip (k) until st. 28 (inset). By st. 32, dorsal (I) and lateral ( $\boldsymbol{m}$ ) views show that Pax6 is expressed in the cerebellar midline nuclei and auricles. Transverse section through the cerebellar midline shows that Pax6 is restricted to granule cell bundles $(\boldsymbol{n})$. At the same stages, $\operatorname{Shh}(\mathbf{0})$ is expressed in lateral sagittal stripes on either side of granule cells, which in transverse section $(\boldsymbol{p})$ is restricted to the pialward cells. In whole mount, faint Ptc2 expression $(\boldsymbol{q})$ maps to that of $\operatorname{Sh}$. In section, Ptc 2 is expressed in the ventricular layer $(\boldsymbol{r})$. These expression domains are summarized $(\boldsymbol{s})$ in a schematic diagram of a midcerebellar transverse section of the dorsal midline. mb, Midbrain; vml, ventral midline. 


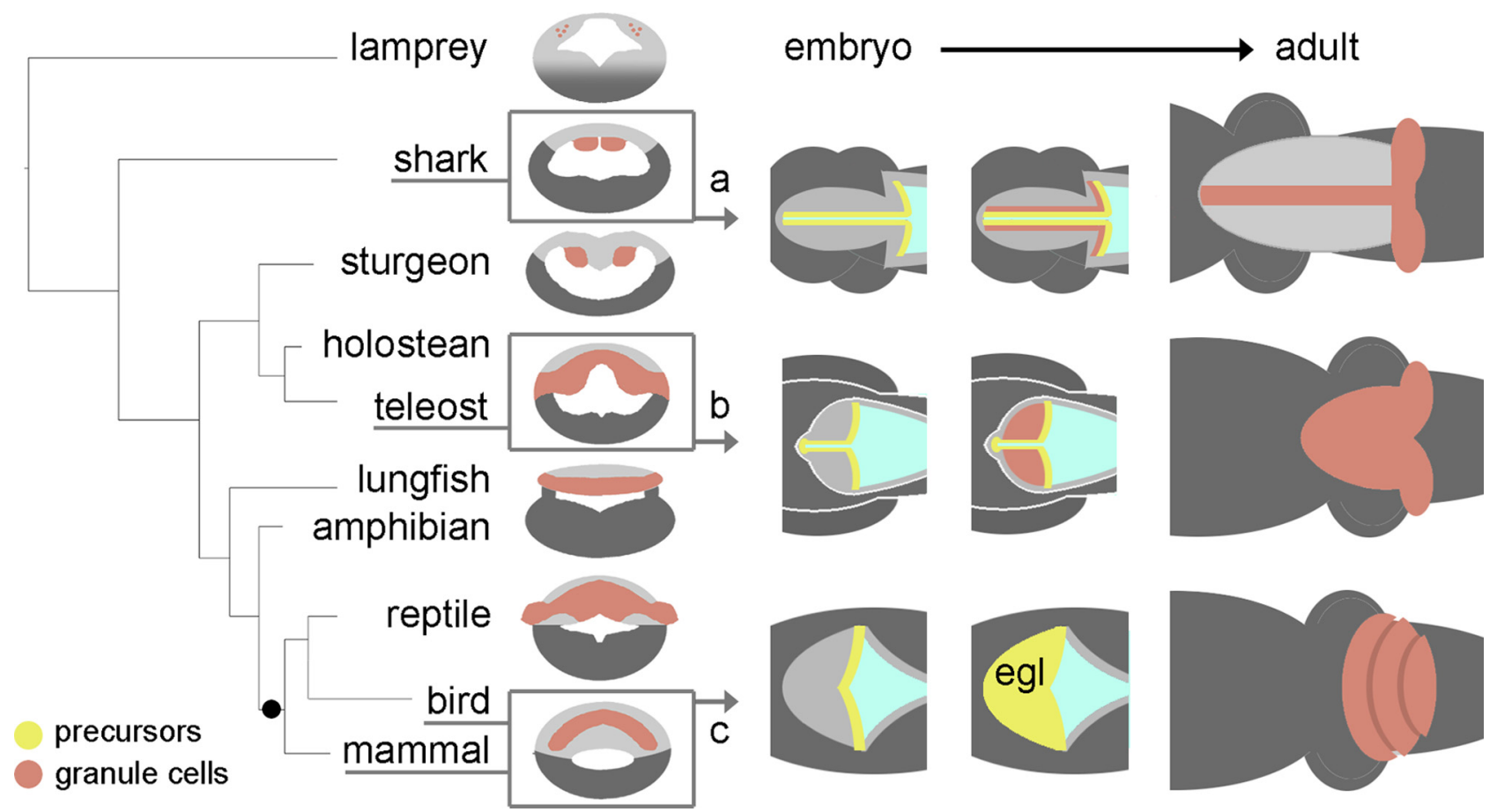

Figure 8. Summary of the evolutionary relationships between selected patterns of granule cell development in vertebrate cerebellum. On the left, a simple phylogenetic tree of vertebrates is contrasted with the distribution of granule cells (brown) in adult cerebellum seen in schematic transverse section (Nieuwenhuys et al., 1998). All jawed vertebrates display a distinct cerebellum containing granule and Purkinje cells. The status of the cerebellum in the jawless lamprey (top) is less clear. To the right, the proposed developmental relationships between granule cell precursors (yellow) and definitive granule neurons are shown in schematic dorsal views for the shark (a), teleost (b), and bird or mammal (c). Our results suggest that an EGL is likely to have evolved as a developmental strategy, after the emergence of amniotes (black dot).

close spatial registration of Shh in the Purkinje cell layer and Ptc2 in the underlying ventricular layer suggestive of Shh signaling pathway between neurons and precursors.

\section{Discussion}

Our observations reveal a distinct pattern of granule cell specification and cell dispersal in zebrafish and the absence of a recognizable EGL. Comparison with the patterning of a shark reveals similarities in Atoh 1 expression that diverge from the mouse and chick model. These results have implications for the zebrafish as an experimental model for cerebellum development (Bae et al., 2009). They also raise questions about the role of transit amplification and migration in generating diversity within the vertebrate CNS.

\section{Zebrafish and shark share a similar plan of granule cell specification}

Cerebellar granule cells are the most numerous neuron in the CNS, and their generation is dependent on Atoh1. Its expression in the early rhombic lip of both hindbrain and cerebellum defines the precursors of the majority of neurons in both the cerebellar and precerebellar circuits (Machold and Fishell, 2005; Wang et al., 2005; Wingate, 2005). Although a large number of genes are expressed specifically in developing granule cells (Millen et al., 1999), Atoh1 has a unique status in that it is essential for the production of an EGL (Ben-Arie et al., 1997). We have hence used the cerebellar expression of Atoh1 to define granule cell precursor identity.

In the zebrafish and shark, domains of Atoh1 expression define areas of intense cell proliferation. This includes the upper rhombic lip, which is a source of granule cells in the zebrafish (Volkmann et al., 2008) and migratory precursors of the EGL in both chick (Wingate and Hatten, 1999) and mouse (Ben-Arie et al., 1997; Machold and Fishell, 2005). In addition, in both zebrafish and sharks, Atohl is expressed continuously along a persistent embryonic cerebellar midline. Correspondingly, the Atoh1-positive midline appears to comprise a significant source of granule cells in both species. In sharks, granule cells form long, paramedian granule cell bundles or eminences. In zebrafish, the midline is a source of migratory derivatives, much the same as the upper rhombic lip. Although our Kaede fate labeling does not allow for a confirmation of the identity of these derivatives, it is a reasonable assumption that late embryonic granule cells could be derived from this Atoh1-positive midline precursor pool. In contrast, in both chick and mouse, the cerebellar midline disappears as the hemispheres fuse (Louvi et al., 2003; Sgaier et al., 2005) to generate an adult cerebellum with no discernable midline. Hemispheric fusion in the chick is associated with the integration of midbrain derivatives of the isthmic "node" into the cerebellar midline (Alexandre and Wassef, 2003). We see similar cell movements in zebrafish, but the role of these cells, which evidently neither promote midline fusion nor give rise to migratory derivatives, is unclear.

Importantly, we see no evidence in either shark or zebrafish of a transient, proliferative, Atoh1-positive superficial layer during cerebellum development. Rather, both species share a similar ground plan of cerebellar development (summarized in Fig. $8 a, b)$. Although a zebrafish "EGL" has been identified previously by a long-term cumulative bromodeoxyuridine uptake (Mueller and Wulliman, 2005), time-lapse analysis of Kaede-mediated fate maps indicates that recently born neurons migrate rapidly away from their proliferation zones (Fig. 4c), making any other technique than acute proliferation assay (such as phosphohistone H3) misleading. Our results show that both zebrafish and shark have proliferation zones at the Atoh1-positive cerebellar midline and upper rhombic lip similar to those implied previously by 
observations in the trout (Pouwels, 1978; Candal et al., 2005), Medaka (Candal et al., 2005), and adult zebrafish (Zupanc et al., 2005; Grandel et al., 2006; Kaslin et al., 2009). Lack of an EGL in the zebrafish is complemented by an absence of Shh signaling in the cerebellum. However, Purkinje cells in the more basal shark express Shh. Because granule cell precursors are not the target of this signal, Shh signaling has an ancestral role in cerebellar development that is distinct from its amniote function of regulating granule cell proliferation.

Our inability to detect late expression of Atoh1 in shark bears some similarity to the downregulation of Atohl in the adult cerebellar stem cell niche of zebrafish (Kaslin et al., 2009). A continuity of granule cell production can be presumed in both instances, raising the possibility that an Atoh1-independent mechanism for the maintenance of the granule cell precursor pool may be a feature of late cerebellar development in both these anamniotes.

\section{Zebrafish granule cells derive from persistent primary proliferation rather than secondary proliferation}

Atoh1 paralogs are segregated into two distinct spatial domains: Atoh1a/b (in the presumptive valvulus) and Atoh1c (cerebellar midline and upper rhombic lip) correspond to expression of $G d f 7$ and $G d f 6 a$, respectively. In mouse, $G d f 7$ is experimentally required for dorsal neural tube structures in mouse (Lee and Jessell, 1999), and correspondingly Atoh 1 can be induced by TGF $\beta$ signals in vitro (Alder et al., 1996, 1999). It therefore seems likely that $G d f 7$ and Gdf6a expression maintains Atoh1a-Atoh1c in the late embryonic zebrafish cerebellum, a hypothesis that could be tested by conditional downregulation of $G d f$ in late stage embryos. If this is the case, there is a mechanistic continuity between proliferation zones in the early and late embryo that suggests they comprise perdurant embryonic tissue rather than a secondary germinal zone. The absence of secondary proliferation in an EGL is supported by both the absence of Shh and the restricted cerebellar expression of N-myc to the Atoh $1 a / b / c$ domain. This indicates that N-myc can promote granule cell proliferation at the rhombic lip independent of Shh signaling (Kenney et al., 2003; Hatton et al., 2006).

Coexpression of Atoh1 $a / b$ and Gdf7 gives the presumptive valvulus a molecular identity that is distinct from the Atohlc/ Gdf6a domain. The mechanism of this unusual coregulation of paired Atoh1 and Gdfhomologs, which is also displayed in anterior neuromasts (Fig. 5), is unclear. Because the valvulus is common to the cerebellum of all euteleosts (Nieuwenhuys et al., 1998), the molecular compartition of its midline may be a common feature of development. Correspondingly, although the presumptive valvulus does not constitute an EGL, its adult derivative maintains a stem cell niche characterized by a subset of granule cell markers (Kaslin et al., 2009). This unique pattern of apical proliferation is a distinguishing feature of the euteleost cerebellum. Furthermore, it is clear that variability in the size and shape of the cerebellum of bony fish principally reflects variability in the size of the valvulus (Schnitzlein and Faucette, 1969; Nieuwenhuys et al., 1998).

\section{Proliferation, transit amplification, and tangential migration as substrates for CNS evolution}

The regional ground plan of the vertebrate CNS is highly conserved (Holland and Holland, 1999), with each region characterized by a stereotyped repertoire of neuronal types (Nieuwenhuys et al., 1998). Given such conservation, how does CNS specialization emerge during development? For the cerebellum, our results suggest that small adjustments to migration and proliferation can result in major morphological differences, which in turn have well characterized functional consequences (Meek, 1992a,b). Thus, in the shark cerebellum, the lack of migration of postmitotic granule neurons away from the midline gives its cerebellum a hyper-elongated structure with granule cells in midline bundles (Fig. 8a). In the teleost (Fig. 8b), amphibian (Gona, 1976), and chick and mouse (Fig. $8 c$ ), tangential migration gives rise to a layer of granule cells. In chick and mouse, migratory rhombic lip derivatives also undergo a second wave of proliferation that results in the characteristic foliated cerebellum. However, the secondary proliferation is neither required for granule cell specification (in shark and zebrafish) nor necessary for a granule cell layer (zebrafish and frog), and thus the EGL is likely to be solely an adaptation for transit amplification. Furthermore, the absence of an EGL in sharks, teleosts (this study), and amphibians (Gona, 1976) suggests that it is an amniote developmental adaptation.

Why did the EGL emerge in amniotes? The answer may lie in the geometry of proliferation. For a given rate of cell division, granule precursors arranged in a layer multiply at an exponential rate (proportional to area) compared with those within a linear rhombic lip (proportional to length). An EGL will therefore allow a threshold number of granule cells to be achieved more quickly. This might comprise a distinct advantage for shorter, definitive embryonic periods in land-adapted amniotes. Intriguingly, transit amplification is also found in the forebrain subventricular zone: a transient, displaced proliferation zone that has similarly been proposed as a site of evolutionary adaptation in the mammalian cortex (Kriegstein et al., 2006; Abdel-Mannan et al., 2008). Transit amplification strategies may hence prove the major target for evolutionary adaptation in generating structural diversity in both the cerebellum and cortex.

In conclusion, our results show that the EGL is remarkable as one of the few, if not the only, major embryonic structures of the vertebrate brain to be added relatively recently in evolution. We can speculate that its origins lie in cell-autonomous adaptation within the ancestral cerebellar rhombic lip precursor that enabled migrating cells to both maintain Atoh1 expression and respond to Shh secreted by Purkinje cells. An intriguing question is whether these innovations occurred by a single gene regulatory step that can still be recognized as specific to the development of the amniote cerebellar rhombic lip. Identification of this adaptation may have important implications for understanding how transit amplification is initiated in normal development and subverted in tumorigenesis.

\section{References}

Abdel-Mannan O, Cheung AF, Molnár Z (2008) Evolution of cortical neurogenesis. Brain Res Bull 75:398-404.

Adolf B, Bellipanni G, Huber V, Bally-Cuif L (2004) atoh1.2 and beta3.1 are two new bHLH-encoding genes expressed in selective precursor cells of the zebrafish anterior hindbrain. Gene Expr Patterns 5:35-41.

Alder J, Cho NK, Hatten ME (1996) Embryonic precursor cells from the rhombic lip are specified to a cerebellar granule neuron identity. Neuron 17:389-399.

Alder J, Lee KJ, Jessell TM, Hatten ME (1999) Generation of cerebellar granule neurons in vivo by transplantation of BMP-treated neural progenitor cells. Nat Neurosci 2:535-540.

Alexandre P, Wassef M (2003) The isthmic organizer links anteroposterior and dorsoventral patterning in the mid/hindbrain by generating roof plate structures. Development 130:5331-5338.

Ando R, Hama H, Yamamoto-Hino M, Mizuno H, Miyawaki A (2002) An optical marker based on the UV-induced green-to-red photoconversion of a fluorescent protein. Proc Natl Acad Sci U S A 99:12651-12656.

Aruga J, Minowa O, Yaginuma H, Kuno J, Nagai T, Noda T, Mikoshiba K (1998) Mouse Zicl is involved in cerebellar development. J Neurosci 18:284-293.

Bae YK, Kani S, Shimizu T, Tanabe K, Nojima H, Kimura Y, Higashijima S, Hibi M (2009) Anatomy of zebrafish cerebellum and screen for mutations affecting its development. Dev Biol 330:406-426.

Ben-Arie N, McCall AE, Berkman S, Eichele G, Bellen HJ, Zoghbi HY (1996) 
Evolutionary conservation of sequence and expression of the bHLH protein Atonal suggests a conserved role in neurogenesis. Hum Mol Genet 5:1207-1216.

Ben-Arie N, Bellen HJ, Armstrong DL, McCall AE, Gordadze PR, Guo Q, Matzuk MM, Zoghbi HY (1997) Math1 is essential for genesis of cerebellar granule neurons. Nature 390:169-172.

Candal E, Anadón R, Bourrat F, Rodríguez-Moldes I (2005) Cell proliferation in the developing and adult hindbrain and midbrain of trout and medaka (teleosts): a segmental approach. Brain Res Dev Brain Res 160:157-175.

Corrales JD, Blaess S, Mahoney EM, Joyner AL (2006) The level of sonic hedgehog signaling regulates the complexity of cerebellar foliation. Development 133:1811-1821.

Dahmane N, Ruiz i Altaba A (1999) Sonic hedgehog regulates the growth and patterning of the cerebellum. Development 126:3089-3100.

Dahn RD, Davis MC, Pappano WN, Shubin NH (2007) Sonic hedgehog function in chondrichthyan fins and the evolution of appendage patterning. Nature 445:311-314.

Davidson AJ, Postlethwait JH, Yan YL, Beier DR, van Doren C, Foernzler D, Celeste AJ, Crosier KE, Crosier PS (1999) Isolation of zebrafish gdf7 and comparative genetic mapping of genes belonging to the growth/differentiation factor 5, 6, 7 subgroup of the TGF-beta superfamily. Genome Res 9:121-129.

Elsen GE, Choi LY, Millen KJ, Grinblat Y, Prince VE (2008) Zicl and Zic4 regulate zebrafish roof plate specification and hindbrain ventricle morphogenesis. Dev Biol 314:376-392.

Espinosa JS, Luo L (2008) Timing neurogenesis and differentiation: insights from quantitative clonal analyses of cerebellar granule cells. J Neurosci 28:2301-2312.

Farner HP (1978) Embryonal development of the brain of the shark Scyliorhinus canicula (L.). I. Formation of the shape of the brain, the migration mode and phase and the structure of the diencephalon (in German). J Hirnforsch 19:313-332.

Gona AG (1976) Autoradiographic studies of cerebellar histogenesis in the bullfrog tadpole during metamorphosis: the external granular layer. J Comp Neurol 165:77-87.

Goodrich LV, Milenković L, Higgins KM, Scott MP (1997) Altered neural cell fates and medulloblastoma in mouse patched mutants. Science 277:1109-1113.

Grandel H, Kaslin J, Ganz J, Wenzel I, Brand M (2006) Neural stem cells and neurogenesis in the adult zebrafish brain: origin, proliferation dynamics, migration and cell fate. Dev Biol 295:263-277.

Hatton BA, Knoepfler PS, Kenney AM, Rowitch DH, de Alborán IM, Olson JM, Eisenman RN (2006) N-myc is an essential downstream effector of Shh signaling during both normal and neoplastic cerebellar growth. Cancer Res 66:8655-8661.

His W (1890) Die entwickelung des menschlichen rautenhirns vom ende des ersten bis zum beginn des dritten monats. I. Verlängertes Mark. Abh Math Phys Kl Kön Sächs Ges d Wiss 29:1-74.

Holland LZ, Holland ND (1999) Chordate origins of the vertebrate central nervous system. Curr Opin Neurobiol 9:596-602.

Kaslin J, Ganz J, Geffarth M, Grandel H, Hans S, Brand M (2009) Stem cells in the adult zebrafish cerebellum: initiation and maintenance of a novel stem cell niche. J Neurosci 29:6142-6153.

Kenney AM, Cole MD, Rowitch DH (2003) Nmyc upregulation by sonic hedgehog signaling promotes proliferation in developing cerebellar granule neuron precursors. Development 130:15-28.

Klein C, Butt SJ, Machold RP, Johnson JE, Fishell G (2005) Cerebellum- and forebrain-derived stem cells possess intrinsic regional character. Development 132:4497-4508.

Knoepfler PS, Cheng PF, Eisenman RN (2002) N-myc is essential during neurogenesis for the rapid expansion of progenitor cell populations and the inhibition of neuronal differentiation. Genes Dev 16:2699-2712.

Kool M, Koster J, Bunt J, Hasselt NE, Lakeman A, van Sluis P, Troost D, Meeteren NS, Caron HN, Cloos J, Mrsić A, Ylstra B, Grajkowska W, Hartmann W, Pietsch T, Ellison D, Clifford SC, Versteeg R (2008) Integrated genomics identifies five medulloblastoma subtypes with distinct genetic profiles, pathway signatures and clinicopathological features. PLoS ONE 3:e3088.

Köster RW, Fraser SE (2006) FGF signaling mediates regeneration of the differentiating cerebellum through repatterning of the anterior hindbrain and reinitiation of neuronal migration. J Neurosci 26:7293-7304.

Kriegstein A, Noctor S, Martínez-Cerdeño V (2006) Patterns of neural stem and progenitor cell division may underlie evolutionary cortical expansion. Nat Rev Neurosci 7:883-890.

Lee KJ, Jessell TM (1999) The specification of dorsal cell fates in the vertebrate central nervous system. Annu Rev Neurosci 22:261-294.

Loeb-Hennard C, Kremmer E, Bally-Cuif L (2005) Prominent transcription of zebrafish $\mathrm{N}$-myc (nmycl) in tectal and retinal growth zones during embryonic and early larval development. Gene Expr Patterns 5:341-347.

Louvi A, Alexandre P, Métin C, Wurst W, Wassef M (2003) The isthmic neuroepithelium is essential for cerebellar midline fusion. Development 130:5319-5330.

Machold R, Fishell G (2005) Math1 is expressed in temporally discrete pools of cerebellar rhombic-lip neural progenitors. Neuron 48:17-24.

Meek J (1992a) Why run parallel fibers parallel? Teleostean Purkinje cells as possible coincidence detectors, in a timing device subserving spatial coding of temporal differences. Neuroscience 48:249-283.

Meek J (1992b) Comparative aspects of cerebellar organisation. Eur J Morphol 30:37-51.

Millen KJ, Millonig JH, Wingate RJ, Alder J, Hatten ME (1999) Neurogenetics of the cerebellar system. J Child Neurol 14:574-581; discussion 581-582.

Mueller T, Wulliman MF (2005) Atlas of early zebrafish brain development. Amsterdam: Elsevier.

Nieuwenhuys R (1967) Comparative anatomy of the cerebellum. In: Progress in brain Research (Fox C, Snider R, eds), pp 1-93. Amsterdam: Elsevier.

Nieuwenhuys R, ten Donkelaar HJ, Nicholson C, eds (1998) The central nervous system of vertebrates. Berlin: Springer.

Pearse RV 2nd, Vogan KJ, Tabin CJ (2001) Ptcl and Ptc2 transcripts provide distinct readouts of Hedgehog signaling activity during chick embryogenesis. Dev Biol 239:15-29.

Pouwels E (1978) On the development of the cerebellum of the trout, Salmo gairdneri. V. Neuroglial cells and their development. Anat Embryol (Berl) 153:67-83.

Ramon y Cajal S (1911) Histologie du Système Nerveux de l'Hommme et des Vertébrés. Paris: Maloine.

Reifers F, Böhli H, Walsh EC, Crossley PH, Stainier DY, Brand M (1998) Fgf8 is mutated in zebrafish acerebellar (ace) mutants and is required for maintenance of midbrain-hindbrain boundary development and somitogenesis. Development 125:2381-2395.

Rodríguez-Moldes I, Ferreiro-Galve S, Carrera I, Sueiro C, Candal E, Mazan S, Anadón R (2008) Development of the cerebellar body in sharks: spatiotemporal relations of Pax6 expression, cell proliferation and differentiation. Neurosci Lett 432:105-110.

Schaper A (1897) Die frühsten differenzierungsvorgänge im centralnervensystem. Arch Entwick-Lungsmech Org 5:81-132.

Schnitzlein HN, Faucette JR (1969) General morphology of the fish cerebellum. In: Neurobiology of cerebellar evolution and development (Llinás R, ed), pp 77-106. Chicago: American Medical Association.

Sgaier SK, Millet S, Villanueva MP, Berenshteyn F, Song C, Joyner AL (2005) Morphogenetic and cellular movements that shape the mouse cerebellum; insights from genetic fate mapping. Neuron 45:27-40.

Sherrington CS (1947) The integrative action of the nervous system, Ed 6. Cambridge, UK: Cambridge UP.

Volkmann K, Rieger S, Babaryka A, Köster RW (2008) The zebrafish cerebellar rhombic lip is spatially patterned in producing granule cell populations of different functional compartments. Dev Biol 313:167-180.

Wallace VA (1999) Purkinje-cell-derived Sonic hedgehog regulates granule neuron precursor cell proliferation in the developing mouse cerebellum. Curr Biol 9:445-448.

Wang VY, Rose MF, Zoghbi HY (2005) Math1 expression redefines the rhombic lip derivatives and reveals novel lineages within the brainstem and cerebellum. Neuron 48:31-43.

Wechsler-Reya RJ, Scott MP (1999) Control of neuronal precursor proliferation in the cerebellum by Sonic Hedgehog. Neuron 22:103-114.

Wingate R (2005) Math-Map(ic)s. Neuron 48:1-4.

Wingate RJ, Hatten ME (1999) The role of the rhombic lip in avian cerebellum development. Development 126:4395-4404.

Wingate RJT (2001) The rhombic lip and early cerebellar development. Curr Opin Neurobiol 11:82-88.

Zupanc GK, Hinsch K, Gage FH (2005) Proliferation, migration, neuronal differentiation, and long-term survival of new cells in the adult zebrafish brain. J Comp Neurol 488:290-319. 